\title{
Veterans Affairs Insurance Disparities for Metastatic Lung Cancer in the Hawaiian Islands
}

John Q. Lin, BS, ${ }^{a}$ Shirley Q. Li, BS, ${ }^{b}$ Todd A. Pezzi, MD, MBA, ${ }^{c}$ Abdallah S. R. Mohamed, MD, ${ }^{C}$ Clifton D. Fuller, MD, PhD, ${ }^{C}$ Aileen B. Chen, $M D,{ }^{C}$ Bruce D. Minsky, MD, ${ }^{c}$ David L. Schwartz, MD, ${ }^{c, e}$ Brenda Y. Hernandez, PhD, ${ }^{d}$ Stephen G. Chun, $M^{\mathrm{C}, *}$

${ }^{a}$ Stanford University School of Medicine, Palo Alto, California

${ }^{b}$ Baylor College of Medicine, Houston, Texas

'Division of Radiation Oncology, University of Texas M.D. Anderson Cancer Center, Houston, Texas

${ }^{d}$ Population Sciences in the Pacific Program, University of Hawaii Cancer Center, Honolulu, Hawai

${ }^{e}$ Department of Radiation Oncology, University of Tennessee Health Sciences Center, Memphis, Tennessee

Received 13 January 2020; accepted 14 January 2020

Available online - 12 February 2020

\section{ABSTRACT}

Introduction: The highest concentration of military personnel in the United States is located in Hawaii where occupational exposures, such as to asbestos in the Pacific Fleet shipyards, predispose them to thoracic malignancies. For this reason, Veterans Affairs (VA) insurance outcomes for lung cancer in Hawaii are of interest.

Methods: All cases of lung cancer in the Hawaii Tumor Registry from 2000 to 2015 were evaluated. The selection criterion included evidence of extensive-stage SCLC (ES-SCLC) or metastatic NSCLC. Overall survival was compared using the Kaplan-Meier log-rank method. Univariate analysis and multivariable analysis (MVA) were carried out to understand the variables associated with overall survival.

Results: There were 434 cases of ES-SCLC and 2139 cases of metastatic NSCLC identified. VA insurance (median survival [MS], 2 mo), Medicaid (MS, 4 mo), and Medicare (MS, 4 mo) had worse survival (log-rank $p<0.001$ ) than private insurance (MS, $8 \mathrm{mo}$ ). In ES-SCLC, VA insurance (hazard ratio [HR], 2.74; 95\% confidence interval [CI]: 1.50-5.01; $p=0.001$ ) and Medicaid (HR, 1.46; 95\% CI: 1.04-2.03; $p=0.027$ ) had significantly worse survival compared with private insurance on MVA. VA insurance (HR, 1.84; 95\% CI: 1.34-2.53; $p<0.001$ ) and Medicaid (HR, 1.40; 95\% CI: 1.20-1.63; $p<0.001$ ) also had worse survival compared with private insurance in metastatic NSCLC on MVA.

Conclusions: VA insurance coverage was associated with dismal survival for metastatic lung cancer that was effectively similar to hospice or supportive care, compelling further investigation to identify reasons for this disparity.
(C) 2020 The Authors. Published by Elsevier Inc. on behalf of the International Association for the Study of Lung Cancer. This is an open access article under the CC BYNC-ND license (http://creativecommons.org/licenses/bync-nd/4.0/).

Keywords: Veterans Affairs; Non-small cell lung cancer; Small cell lung cancer; Hawaii

${ }^{*}$ Corresponding author.

Mr. Lin and Ms. Li contributed equally to this work.

Disclosure: Dr. Chun is a consultant for AstraZeneca; Dr. Fuller has received direct industry grant support and travel funding from Elekta $A B$. He has also received funding unrelated to this project from the National Institutes of Health (NIH), including National Institute for Dental and Craniofacial Research Establishing Outcome Measures award (1R01DE025248/R56DE025248) and an Academic Industrial Partnership grant (3R01DE028290-01); National Cancer Institute (NCI) Early Phase Clinical Trials in Imaging and Image-Guided Interventions Program (5R01CA218148-02); and the NIH Big Data to Knowledge Program of the $\mathrm{NCl}$ Early Stage Development of Technologies in Biomedical Computing, Informatics, and Big Data Science award (5R01CA214825-03) and (1R01EB025026-01). The remaining authors declare no conflict of interest.

Address for correspondence: Stephen G. Chun, MD, Division of Radiation Oncology, The University of Texas MD Anderson Cancer Center 1515 Holcombe Blvd., Houston, Texas 77030. E-mail: sgchun@ mdanderson.org

Cite this article as: Lin JQ, et al. Veterans Affairs Insurance Disparities for Metastatic Lung Cancer in the Hawaiian Islands. JTO Clin Res Rep 1:100003

(c) 2020 The Authors. Published by Elsevier Inc. on behalf of the International Association for the Study of Lung Cancer. This is an open access article under the CC BY-NC-ND license (http:// creativecommons.org/licenses/by-nc-nd/4.0/).

ISSN: 2666-3643

https://doi.org/10.1016/j.jtocrr.2020.100003 


\section{Introduction}

The Department of Veterans Affairs (VA) is the largest integrated health care system in the United States with over 7000 lung cancer cases seen annually. ${ }^{1} \mathrm{~Pa}-$ tients with lung cancer in the VA system present with more advanced disease than the general population, ${ }^{1}$ making them disproportionately vulnerable to delayed or inadequate care. Although VA insurance provides a large number of veterans access to health care, appointment delays and suboptimal care have long been criticisms of the VA. ${ }^{2}$

The most concentrated military population in the United States is located in the Hawaiian Islands where roughly 100,000 military personnel represent $8 \%$ of the population. ${ }^{3}$ For this reason, the Hawaii Tumor Registry (HTR) is uniquely suited for comparing VA insurance outcomes with those of other payer types. In the HTR, VA insurance survival is distinctly coded, making comparative outcomes readily discernible. Moreover, lung cancer outcomes in the Hawaiian VA population are of interest because of the large-scale asbestos exposure in the Pearl Harbor Pacific Fleet naval shipyards. ${ }^{4}$

Given the challenges VA patients face in accessing care, we hypothesized that differential outcomes would be present in the VA-insured population for metastatic lung cancer in the Hawaiian Islands. In this analysis, we intentionally focus on high-risk patients with metastatic lung cancer, cases in which access to and quality of care can rapidly translate to disparate oncologic outcomes. For these reasons, we use the HTR to compare VA insurance outcomes for metastatic lung cancer in the Hawaiian Islands with other primary insurance types.

\section{Materials and Methods}

The HTR is maintained by the University of Hawaii Cancer Center as part of the Surveillance, Epidemiology, and End Results program with data coded per Surveillance, Epidemiology, and End Results definitions. Institutional review board approval was obtained for this retrospective HTR analysis from the University of Hawaii Cancer Center. A total of 1366 SCLC and 9088 NSCLC cases were identified from 2000 to 2015 . The selection criterion included evidence of metastatic disease as per the American Joint Commission on Cancer version 6 or 7 for which the primary insurance payer status and survival were known. Military Tricare insurance was recoded as a private insurance and the uninsured were excluded from this analysis. Survival was compared using the Kaplan-Meier method and log-rank analysis. Factors associated with overall survival were evaluated by univariate analysis (UVA) and the appropriate variables significantly associated with survival were included in multivariable analysis (MVA) fitted to the
Cox proportional hazards model. Data were analyzed using R 3.5.3 (R foundation for statistical computing). Statistical significance was considered for $p$ values less than 0.05 .

\section{Results}

A total of 2573 cases of metastatic lung cancer that met the selection criterion, of which 434 were extensivestage (ES)-SCLC and 2139 metastatic NSCLC, were identified in the HTR. The baseline characteristics were determined (Supplementary Table 1); the median age for ES-SCLC was 69 years and for metastatic NSCLC was 70 years. About $58 \%$ of patients were men in both cohorts. The primary insurance at diagnosis was $32.3 \%$ private $(\mathrm{N}=832), 52.1 \%$ Medicare $(\mathrm{N}=1341), 13.1 \%$ Medicaid $(\mathrm{N}=338)$, and $2.4 \%$ VA $(\mathrm{N}=62)$.

In the ES-SCLC group, $22.8 \%$ had bone metastases, $19.4 \%$ had brain metastases, $29.3 \%$ had liver metastases, and $15.9 \%$ had lung metastases at initial diagnosis (Supplementary Table 1). During the initial oncologic treatment, chemotherapy was administered in $65.9 \%$ and radiation in $39.6 \%$ of the cases. Evaluation of the demographic characteristics of the ES-SCLC group revealed that $50.7 \%$ were married, $32.7 \%$ were white, 41\% were Asian, and 25.8\% were Pacific Islander.

In the metastatic NSCLC cohort, $27.6 \%$ had bone metastases, $19.8 \%$ had brain metastases, $11.5 \%$ had liver metastases, and $23 \%$ had lung metastases at diagnosis (Supplementary Table 1). Chemotherapy was administered in $52.5 \%$ and radiation in $45.2 \%$ of the cases as part of initial oncologic management. Demographics of the group revealed that $55.4 \%$ were married, $53.1 \%$ were Asian, $25.4 \%$ were white, $19.8 \%$ were Pacific Islander, and 1.1\% were black. Patients with Medicare (median survival [MS], 4 mo), Medicaid (MS, 4 mo), and VA insurance (MS, $2 \mathrm{mo}$ ) had significantly worse survival than those with private insurance (MS, 8 mo, log-rank, $p<0.001$ ) in the combined ES-SCLC and metastatic NSCLC group (Fig. 1A). VA insurance also had significantly worse overall survival than either Medicaid or Medicare insurance (log-rank, $p<0.001$ ). UVA was then used to identify variables associated with overall survival in ES-SCLC and metastatic NSCLC (Supplementary Tables 2 and 3).

In ES-SCLC (Fig. 1B), patients with private insurance had better overall survival (MS, 7 mo) than those with Medicare (MS, 6 mo, $p=0.004$ ), Medicaid (MS, 4 mo, $p=0.007$ ), or VA insurance (MS, 1 mo, $p<0.001$ ). On MVA of the ES-SCLC group (Table 1), VA insurance (hazard ratio [HR], 2.74; 95\% confidence interval [CI]: $1.50-5.01 ; p=0.001$ ) and Medicaid insurance (HR, 1.46; 95\% CI: $1.04-2.03 ; p=0.027$ ) were associated with significantly worse overall survival, whereas Medicare 

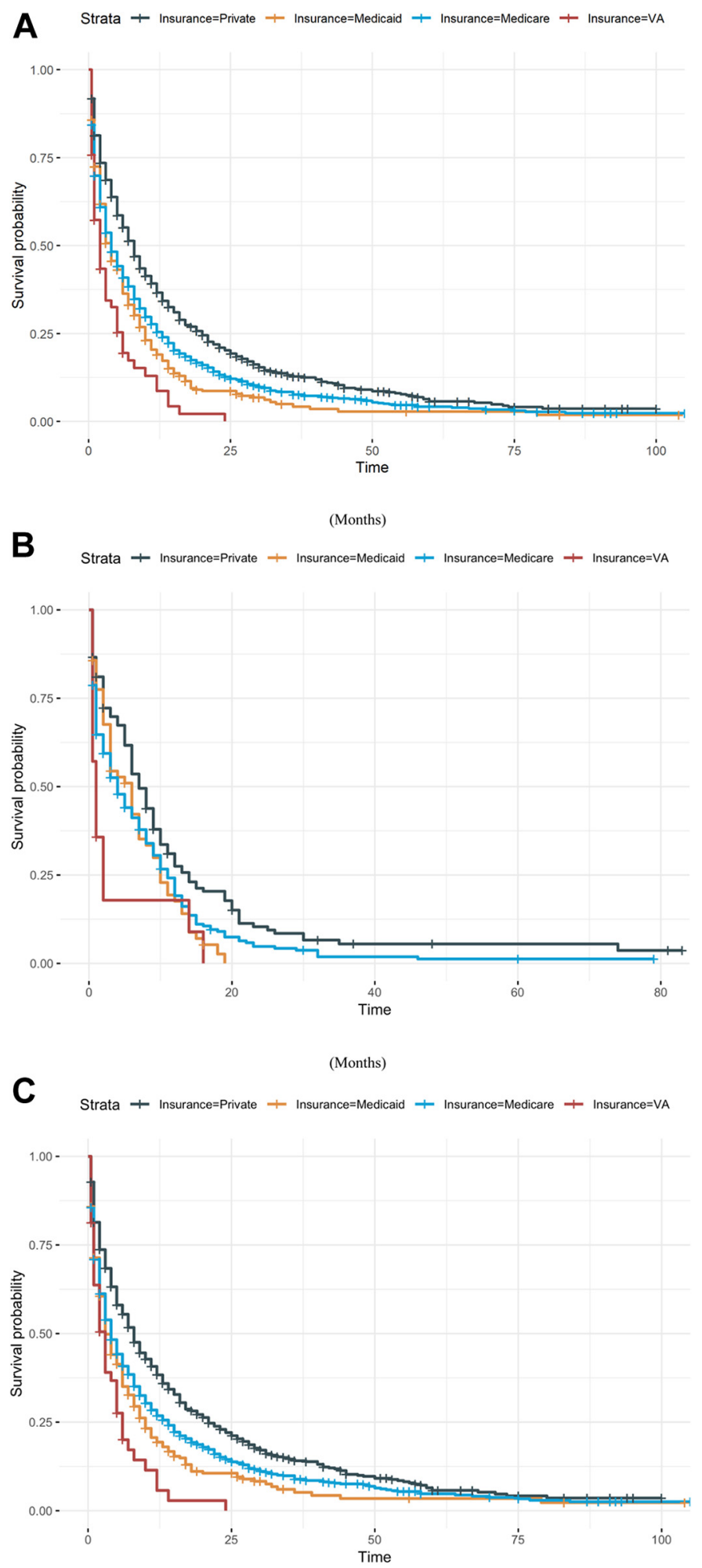

(Months)

Figure 1. Survival by primary insurance type in the Hawaii Tumor Registry, 2000 to 2015 for metastatic lung cancer. (A) Kaplan-Meier survival estimates for all metastatic lung cancers by insurance status. (B) Kaplan-Meier survival estimates for extensive-stage SCLC by insurance status. (C) Kaplan-Meier survival estimates for metastatic NSCLC by insurance status. VA, Veterans Affairs. 


\begin{tabular}{|c|c|c|c|}
\hline Parameter & $p$ Value & HR & $95 \% \mathrm{Cl}$ \\
\hline \multicolumn{4}{|l|}{ Insurance Status } \\
\hline Veterans Affairs & 0.001 & 2.74 & $1.50-5.00$ \\
\hline Medicare & 0.538 & 1.09 & $0.83-1.42$ \\
\hline Medicaid & 0.027 & 1.46 & $1.04-2.03$ \\
\hline Age at diagnosis (continuous) & $<0.001$ & 1.03 & $1.02-1.05$ \\
\hline \multicolumn{4}{|l|}{ Marital status } \\
\hline Separated or divorced & 0.043 & 0.69 & $0.48-0.99$ \\
\hline Married & 0.004 & 0.65 & $0.48-0.87$ \\
\hline Widowed & 0.033 & 0.66 & $0.45-0.97$ \\
\hline Unknown & 0.803 & 0.88 & $0.31-2.44$ \\
\hline \multicolumn{4}{|l|}{$\begin{array}{l}\text { Liver metastasis at diagnosis } \\
\text { No (ref) }\end{array}$} \\
\hline Yes & 0.001 & 1.56 & $1.19-2.05$ \\
\hline Unknown & 0.66 & 1.93 & $0.86-4.30$ \\
\hline \multicolumn{4}{|l|}{$\begin{array}{l}\text { Brain metastasis at diagnosis } \\
\text { No (ref) }\end{array}$} \\
\hline Yes & 0.22 & 0.83 & $0.62-1.11$ \\
\hline Unknown & 0.16 & 0.57 & 0.27-1.24 \\
\hline
\end{tabular}

$\mathrm{HR}$, hazard ratio; $\mathrm{Cl}$, confidence interval; ref, reference level.

had no significant impact (HR, 1.09; 95\% CI: 0.83-1.42; $p=0.538$ ). On UVA, there was a lower likelihood of chemotherapy delivery with VA insurance compared with private insurance for ES-SCLC (OR, 0.25; 95\% CI: $0.08-0.78 ; p=0.021$ ).

In metastatic NSCLC (Fig. 1C), patients with Medicare (MS, 4 mo, $p<0.001$ ), Medicaid (MS, 3 mo, $p<0.001$ ), and VA insurance (MS, 3 mo, $p<0.001$ ) had worse overall survival than those with private insurance (MS, 8 mo). MVA revealed that VA insurance (HR, 1.84; 95\% CI: 1.34-2.53; $p<0.001$ ) and Medicaid insurance (HR, 1.40; 95\% CI: $1.20-1.63 ; p<0.001)$ were associated with worse survival than private insurance (Table 2) but Medicare was not (HR, 1.01; 95\% CI: 0.89-1.15; $p=0.838$ ). Less use of chemotherapy was also observed with VA insurance in NSCLC (OR, 0.19; 95\% CI: 0.10$0.36 ; p<0.001$ ) compared with private insurance.

\section{Discussion}

VA insurance coverage was associated with dismal survival rates for metastatic lung cancer in the Hawaiian Islands, warranting further investigation into the root cause of this disparity. The overall survival for VA insurance was significantly worse than that for any other insurance and was effectively similar to that of hospice or supportive care. The dramatic disparity in survival seen for VA-insured patients in Hawaii may be appropriate for additional scrutiny under the VA Quality Enhancement Research Initiative. ${ }^{5}$ Our findings come at
Table 2. Multivariable Analysis of Factors Associated With Survival in Metastatic NSCLC in the Hawaii Tumor Registry

\begin{tabular}{|c|c|c|c|}
\hline & $p$ Value & HR & $95 \% \mathrm{Cl}$ \\
\hline \multicolumn{4}{|l|}{ Insurance status } \\
\hline \multicolumn{4}{|l|}{ Private (ref) } \\
\hline Veterans Affairs & $<0.001$ & 1.84 & $1.34-2.53$ \\
\hline Medicare & 0.838 & 1.01 & $0.89-1.15$ \\
\hline Medicaid & $<0.001$ & 1.40 & $1.20-1.63$ \\
\hline Age at diagnosis (continuous) & $<0.001$ & 1.02 & $1.02-1.03$ \\
\hline \multicolumn{4}{|l|}{ Sex } \\
\hline \multicolumn{4}{|l|}{ Male (ref) } \\
\hline Female & $<0.001$ & 0.79 & $0.71-0.86$ \\
\hline \multicolumn{4}{|l|}{ Ethnicity } \\
\hline \multicolumn{4}{|l|}{ White (ref) } \\
\hline Black & 0.256 & 0.76 & $0.48-1.21$ \\
\hline Asian & 0.001 & 0.83 & $0.74-0.93$ \\
\hline Pacific Islander & 0.652 & 1.03 & $0.90-1.19$ \\
\hline Other & 0.205 & 1.43 & $0.82-2.49$ \\
\hline \multicolumn{4}{|l|}{ AJCC M-stage } \\
\hline \multicolumn{4}{|l|}{ M1a (ref) } \\
\hline M1b & 0.238 & 1.09 & $0.94-1.27$ \\
\hline M1 NOS & 0.508 & 0.90 & $0.67-1.22$ \\
\hline \multicolumn{4}{|l|}{ AJCC $N$-stage } \\
\hline \multicolumn{4}{|l|}{ NO (ref) } \\
\hline $\mathrm{N} 1$ & 0.170 & 0.86 & $0.70-1.07$ \\
\hline N2 & 0.002 & 1.22 & $1.07-1.37$ \\
\hline N3 & 0.003 & 1.23 & $1.08-1.41$ \\
\hline$N X$ & 0.105 & 1.16 & $0.97-1.39$ \\
\hline \multicolumn{4}{|l|}{ Liver metastasis at diagnosis } \\
\hline \multicolumn{4}{|l|}{ No (ref) } \\
\hline Yes & $<0.001$ & 1.57 & $1.34-1.83$ \\
\hline Unknown & 0.861 & 1.03 & $0.74-1.44$ \\
\hline \multicolumn{4}{|l|}{ Bone metastasis at diagnosis } \\
\hline \multicolumn{4}{|l|}{ No (ref) } \\
\hline Yes & 0.056 & 1.14 & $1.00-1.30$ \\
\hline Unknown & 0.037 & 1.43 & $1.02-2.00$ \\
\hline
\end{tabular}

$\mathrm{HR}$, hazard ratio; $\mathrm{Cl}$, confidence interval; ref, reference level; NOS, not otherwise specified; AJCC, American Joint Commission on Cancer.

an opportune time given the ongoing efforts to reform the VA medical system in the wake of the 2014 Phoenix VA scandal, including the Veterans Choice Program, ${ }^{6-8}$ and the VA Mission Act. ${ }^{9}$

Previous analyses have evaluated VA lung cancer quality of care, but none have shown as dramatic a disparity as our findings. An analysis of the Pennsylvania population reported a 3\%-worse survival for VA when compared with civilian patients with lung cancer. ${ }^{10}$ Another analysis by the Institute for Population Health Improvement of the California population also reported favorable outcomes for VA care in lung cancer. ${ }^{11}$ Other analyses have also shown reasonable outcomes for elderly patients with cancer treated in the VA system ${ }^{12,13}$ and for other cancers such as colorectal cancer. ${ }^{14,15}$ As such, VA insurance outcomes in Hawaii might not be generalizable to the entire VA system but may represent an opportunity for targeted policy intervention. 
There are limitations to this analysis, including the small VA insurance sample size and lack of performance status or comorbidity score captured in the HTR. It is possible that poor outcomes could be entirely explained by performance status or another factor not captured in the HTR. However, even with marginal performance status and confounding medical comorbidities, better MS would be expected than that observed in the Hawaiian VA-insured population. Regardless of the limitations of this analysis, the findings compel further investigation to identify a reason for this disparity.

VA-insured patients in the Hawaiian Islands with metastatic lung cancer had poor survival, meriting additional investigation to better understand these findings. Understanding this disparity may have significant health policy implications for veterans of the Hawaiian Islands.

\section{Acknowledgments}

Dr. Fuller and Dr. Mohamed received funding and salary support from the National Institutes of Health (NIH), including the National Institute for Dental and Craniofacial Research award (1R01DE025248/R56DE025248); a National Science Foundation, Division of Mathematical Sciences, Joint NIH/NSF Initiative on Quantitative Approaches to Biomedical Big Data grant (NSF 1557679); the NIH Big Data to Knowledge Program of the National Cancer Institute (NCI) Early Stage Development of Technologies in Biomedical Computing, Informatics, and Big Data Science award (1R01CA214825); and NCI Early Phase Clinical Trials Imaging in and Image-Guided Interventions Program (1R01CA218148). Dr. Fuller also received a National Institute of Biomedical Imaging and Bioengineering Research Education Programs for Residents and Clinical Fellows grant (R25EB025787-01); an NIH/NCI Cancer Center Support Grant Pilot Research Program award from the UT MD Anderson Cancer Center Support Grant Radiation Oncology and Cancer Imaging Program (P30CA016672); and an NIH/NCI Head and Neck Specialized Programs of Research Excellence Developmental Research Program award (P50 CA097007. Dr. Minsky is the co-chair emeritus of the NCI Gastrointestinal Steering Committee and received funding from U10 CA180858-0- NCI National Clinical Trials Network Lead Academic Participating Site and 2U19CA021239-35 NCI Improving the Clinical Effectiveness and Understanding of the Biophysical Basis of Protons.

\section{Supplementary Data}

Note: To access the supplementary material accompanying this article, visit the online version of the Journal of Thoracic Oncology Clinical and Research Reports at www.jtocrr.org and at https://doi.org/10.1016/j.jtocrr.2 020.100003.

\section{References}

1. Zullig LL, Jackson GL, Dorn RA, et al. Cancer incidence among patients of the U.S. Veterans Affairs health care system. Mil Med. 2012;177:693-701.

2. Fulton LV, Brooks MS. An evaluation of alternatives for providing care to Veterans. Healthcare (Basel). 2018;6:E92.

3. Oyama N, Nishi S, Schmitt RC. Population characteristics of Hawaii, 1982. Popul Rep. 1984:1-14.

4. Kolonel LN, Yoshizawa CN, Hirohata T, Myers BC. Cancer occurrence in shipyard workers exposed to asbestos in Hawaii. Cancer Res. 1985;45:3924-3928.

5. Stetler CB, Mittman BS, Francis J. Overview of the VA quality enhancement research initiative (QUERI) and QUERI theme articles: QUERI Series. Implement Sci. 2008;3:8.

6. Department of Veterans Affairs. Expanded Access to non-VA Care through the Veterans choice program. Final rule. Fed Regist. 2018;83:21893-21897.

7. Gellad WF. The veterans choice act and dual health system use. J Gen Intern Med. 2016;31:153-154.

8. Zullig LL, Goldstein KM, Bosworth HB. Changes in the delivery of Veterans Affairs cancer care: ensuring delivery of coordinated, quality cancer care in a time of uncertainty. J Oncol Pract. 2017;13:709-711.

9. Reddy A, Fihn SD, Liao JM. The VA MISSION act - creating a center for innovation within the VA. N Engl J Med. 2019;380:1592-1594.

10. Campling BG, Hwang WT, Zhang J, et al. A populationbased study of lung carcinoma in Pennsylvania: comparison of Veterans administration and civilian populations. Cancer. 2005;104:833-840.

11. May FP, Yu C, Kaunitz J. High quality of cancer care in the department of Veterans Affairs (VA). Am J Cancer Res. 2018;8:761-762.

12. Keating NL, Landrum MB, Lamont EB, et al. Quality of care for older patients with cancer in the veterans health administration versus the private sector: a cohort study. Ann Intern Med. 2011;154:727-736.

13. Landrum MB, Keating NL, Lamont EB, et al. Survival of older patients with cancer in the Veterans health administration versus fee-for-service Medicare. J Clin Oncol. 2012;30:1072-1079.

14. Zullig LL, Carpenter WR, Provenzale D, Weinberger M, Reeve BB, Jackson GL. Examining potential colorectal cancer care disparities in the Veterans Affairs health care system. J Clin Oncol. 2013;31:3579-3584.

15. Zullig LL, Jackson GL, Weinberger M, Provenzale D, Reeve BB, Carpenter WR. An examination of racial differences in process and outcome of colorectal cancer care quality among users of the Veterans Affairs health care system. Clin Colorectal Cancer. 2013;12:255-260. 